\title{
SYNTACTIC PRIMING AND ESL QUESTION DEVELOPMENT
}

\author{
Kim McDonough \\ Northern Arizona University
}

\author{
Alison Mackey \\ Georgetown University
}

\begin{abstract}
Interaction research that has investigated the relationship between language production and second language (L2) development has largely focused on learners' immediate responses to interactional feedback. However, other speech production processes might help account for the beneficial relationship between interaction and L2 development. The current study examines whether syntactic priming the tendency to produce a syntactic structure encountered in the recent discourse - is associated with English as a second language (ESL) question development. The participants were intermediatelevel Thai learners of English $(N=46)$ at a large public university in northern Thailand. In two 20-min sessions, the participants carried out communicative activities with a more advanced L2 English interlocutor who had been scripted with developmentally advanced question forms. They also completed an oral pretest and two posttests that consisted of activities similar to those carried out during the treatment sessions. The results indicated that participants who evidenced high levels of syntactic priming were likely to advance to a higher stage in the developmental sequence of ESL question formation.
\end{abstract}

The interaction hypothesis of SLA (Gass, 2003; Gass \& Mackey, 2007; Long, 1996; Pica, 1994) states that second language (L2) learning is facilitated through interaction that brings together input features (e.g., interactional feedback), internal learner capacities (e.g., attention), and language output. More than 40 studies and two meta-analyses (Keck, Iberri-Shea, Tracy-Ventura, \& Wa-Mbaleka, 2006; Mackey \& Goo, 2007) have reported that interaction facilitates L2

Address correspondence to: Kim McDonough, P.O. Box 6032, English Department, Northern Arizona University, Flagstaff, AZ 86011-6032; e-mail: kim.mcdonough@nau.edu. 
learning. Researchers have proposed a number of reasons why interaction brings about positive L2 learning outcomes. For example, it can provide interactional feedback (Long, 2006), enhance the salience of positive evidence (Leeman, 2003), raise learners' awareness of language form (Ellis, 1991; Gass, 1997, 2003; Long, 1996; Schmidt, 1995, 2001; Swain \& Lapkin, 1995), and create opportunities for learners to produce the target language and modify their inappropriate or ungrammatical utterances (Swain, 1995, 2000, 2005).

Interaction research that examines the role of language production in L2 learning has focused narrowly on learners' responses to interactional feedback, with several studies reporting positive associations between learners' responses and developmental outcomes (e.g., Havranek, 2002; Loewen \& Philp, 2006; McDonough, 2005; McDonough \& Mackey, 2006). Most of this research has investigated learners' responses to interactional feedback in the form of (a) repetition of recasts and (b) reformulation of previous utterances, both of which occur in the turn immediately following the feedback move. However, McDonough and Mackey also investigated primed production, which they defined as a learner's production of a new utterance using the syntactic structure modeled in an interlocutor's recast. This type of response involved the production of a new utterance with the syntactic structure provided by the interlocutor, rather than the reformulation of a learner's previous utterance or the repetition of an interlocutor's recast. They reported that both recasts and primed production were associated with English as a second language (ESL) question development, whereas immediate repetition of recasts was not. What is not clear from their study, and what motivated the current study, is whether primed production in the absence of any interactional feedback is also associated with ESL question development.

Studying primed production, as opposed to reformulations or repetitions of recasts, is motivated by first language (L1) speech production research in syntactic priming. Syntactic priming is characterized by a speaker's tendency to produce a syntactic structure encountered in the recent discourse, as opposed to an alternate structure. The idea is that speakers are sensitive to experiences with a syntactic structure rather than to repeated experiences with surface-level features. An example of syntactic priming in L2 speech production is illustrated in (1).

(1) Syntactic priming (numbers in brackets indicate turn number)

[95] Speaker 1: The man shows his wife the boot.

[96] Speaker 2: A teacher is teaching some kids a game. (McDonough, 2006, p. 182)

In this task, two English L2 speakers were taking turns describing pictures to each other. In the first turn, speaker 1 produced a double-object dative to describe a picture of a man showing his boot to a woman. In the next turn, speaker 2 similarly produced a double-object dative to describe her picture. Although speaker 2 could have used a prepositional dative or a single-object dative construction, she produced a sentence that had the same syntactic 
structure as her interlocutor's utterance. Syntactic priming has been found to occur even when the initial and subsequent utterances have different topics, lexical items, closed-class elements, thematic compositions, phonology, and pragmatic features (Bock, 1986, 1989, 1990; Bock \& Loebell, 1990; Bock, Loebell, \& Morey, 1992; Hare \& Goldberg, 1999) and also even when there is intervening material between the initial and subsequent utterances (Bock \& Griffin, 2000; Branigan, Pickering, Stewart, \& McLean, 2000; Huttenlocher, Vasilyeva, \& Shimpi, 2004). For example, in Bock and Griffin's study, even when the initial and subsequent utterances were separated by up to 10 unrelated intervening sentences, syntactic priming still occurred.

Current research in L1 speech production is exploring the mechanisms responsible for syntactic priming. Although Bock (1989) initially speculated that syntactic priming might occur as the result of residual activation of the mechanisms involved in speech production, subsequent research demonstrated that it occurs even when speakers simply hear a particular syntactic form. More recently, researchers have argued that syntactic priming might be due to residual activation of the morphosyntactic information stored with individual lexical items (Branigan, Pickering, Liversedge, Stewart, \& Urbach, 1995; Pickering \& Branigan, 1998). Also, because this linguistic information is shared by the comprehension and production systems, either previously heard or spoken syntactic structures can facilitate subsequent production. In other words, when a speaker hears or produces an utterance with a specific lexical item in one of its possible syntactic structures, that syntactic information becomes activated and facilitates the subsequent production of that same syntactic structure with other lexical items. Additionally, simply hearing a lexical item that only allows one syntactic structure might be sufficient to lead a speaker to produce that structure with subsequent lexical items that allow alternative structures (Melinger \& Dobel, 2005).

Syntactic priming is interesting for L2 learning for several reasons. Whereas L1 speakers often alternate between two equally acceptable syntactic structures, such as a double-object dative or a prepositional dative, L2 learners often face choices that involve developmentally simple or advanced forms, nontargetlike or targetlike forms, and more appropriate or less appropriate forms. These choices are illustrated in (2) and (3), in which a participant in the current study was carrying out communicative tasks with another English L2 speaker. Throughout the conversation the learner alternated between two forms of $w h$-questions: questions with a fronted $w h$-word without the copula and questions with a fronted $w h$-word and the copula. These forms are stage three and four questions, respectively, in Pienemann and Johnston's (1987) developmental sequence for ESL question formation.

(2) Wh-fronting without copula

What your favorite holiday?

What movie that you see the last time?

What color of the scarf? 
(3) Wh-fronting with copula

What is the meaning of number 11 on the wall?

What time is it?

Who is it?

In this situation, syntactic priming might lead the learner to produce the developmentally advanced structure rather than the less advanced structure. By facilitating the production of developmentally advanced structures, syntactic priming might strengthen the knowledge representations that learners already have stored (Nobuyoshi \& Ellis, 1993) and encourage automatic retrieval of linguistic forms (de Bot, 1996).

Another possible contribution of syntactic priming to SLA concerns the formation of more abstract syntactic representations. In usage-based approaches to acquisition, development proceeds from formulaic expressions to a limited-scope pattern and, finally, to abstract representations. In L1 acquisition research, Tomasello (2000) has argued that in an early stage of linguistic development (about 2-2.5 years), children have only weak syntactic representations that are associated primarily with specific lexical items. Only after further exposure to the type and token frequency with which certain linguistic structures appear in the input do children's linguistic representations gradually grow in strength and abstractness. For L2 speakers who produce a syntactic form only as a formulaic utterance or as a limited-scope pattern, syntactic priming might lead them to produce that form with a wider variety of lexical items, which could facilitate the acquisition of more abstract representations. In other words, syntactic priming might facilitate the production of a particular syntactic form across lexical items, thereby helping L2 learners recognize that the syntactic form represents a general category rather than a lexically specific construction (Ellis, 1998, 2002a, 2002b, 2005).

Due to the fact that one of the goals of interaction research is to understand why interaction is developmentally helpful, a logical question is whether language production in the form of syntactic priming facilitates L2 development. As mentioned previously, McDonough and Mackey (2006) found that primed production was positively associated with ESL question development. However, in their study, primed production occurred in an interactive context in which native English speakers also provided learners with recasts that targeted developmentally advanced question forms. Consequently, it is difficult to determine whether primed production alone would also facilitate development. Although previous interaction research has suggested that models might not be particularly beneficial for L2 learning when compared to interactional feedback (Iwashita, 2003; Long, Inagaki, \& Ortega, 1998), these studies did not examine learners' subsequent production of the structures that had been modeled. The current study is expected to shed more light on possible relationships among models, primed production, and L2 development, exploring whether syntactic priming in the absence of interactional feedback facilitates ESL question development. The research question guiding the 
study was: Is there a relationship between syntactic priming and ESL question development?

\section{METHOD}

\section{Participants}

English as a Foreign Language Participants. The participants were 46 undergraduate students (37 women and 9 men) at a large public university in northern Thailand. They were studying in the following bachelor degree programs: education (20), agro-industry (14), humanities (6), business administration (3), economics (2), and engineering (1). They were all native speakers of Thai. Their ages ranged from 19 to 21 years, with an average of 19.7 years. Their amount of previous English study ranged from 8 to 18 years, with an average of 12.3 years. Most of the participants (35/46) did not report knowledge of any L2 other than English, but 11 participants had studied a foreign language, including German (5), Japanese (3), Chinese (2), and French (1). Only five participants had ever been to a country where English was spoken as a native language, and they reported a length of residence ranging from 4 days to 3 months. They were recruited from four intact classes of an oral communication course for non-English majors, which they were taking as either a requirement or an elective, depending on their degree program.

Scripted Interlocutors. The participants interacted with six scripted interlocutors (five women and one man) who were undergraduate students at the same university. The scripted interlocutors were juniors and seniors who were studying for bachelor degrees in English. As English majors, they had completed many more English courses than the participants. Their curriculum included both skill-focused courses, such as oral communication and writing, and content-based courses, such as phonetics, syntax, and literature. They were invited to assist with the data collection based on the recommendation of their psycholinguistics instructor and were paid to interact with the participants. One of the researchers had a 90-min meeting with the scripted interlocutors during which they learned about (a) syntactic priming, (b) the purpose of the study, (c) the communicative activities they would carry out with the English as a foreign language learners, (d) the types of questions they were to ask, and (e) the scripts for each activity.

\section{Target Structure}

The target structure was question formation, which was selected in order to facilitate comparison with previous research that has explored the relationship between interactional feedback and ESL question development (e.g., Mackey, 1999; McDonough, 2005; Silver, 2000; Spada \& Lightbown, 1999). Moreover, the development of question forms has been shown to correlate well 
with SLA in general (Pienemann, 1998, 2007), making it a dependable indicator of a L2 learner's development of the target language. ESL question development was operationalized as a learner's movement to a higher stage in Pienemann and Johnston's (1987; Pienemann, Johnston, \& Brindley, 1988) developmental sequence for ESL question formation as evidenced by the production of at least two linguistically and contextually unique questions from a higher stage. The following developmental sequence, taken from Pienemann and Johnston (1987), was used in this study: stage 3 = fronting (e.g., Why she do that?), stage $4=$ pseudo-inversion/yes-no inversion (e.g., Where are they now?), and stage 5 = aux-second (e.g., What have you got?). As Mackey has pointed out, defining development as a learner's movement to a higher stage in this sequence allows researchers to assess and control learners' readiness to acquire certain forms.

\section{Design}

The study used a pretest-posttest design to explore the relationship between syntactic priming and ESL question development. Because the dependent variable under investigation-syntactic priming-is contingent upon learner behavior, it was not possible to determine a priori whether it would occur. Consequently, the treatment activities created contexts for syntactic priming to occur, and each participant's performance was subsequently analyzed to determine the extent to which it had occurred. One of the four oral communication classes was randomly selected to serve as the control group, and students in that class completed the pretest and posttests only. The students in the remaining three classes were assigned to the priming group. Participants in the priming group completed the pretest and posttests and carried out communicative activities with the scripted interlocutors during two 20-min sessions. The scripted interlocutors had scripts containing developmentally advanced questions for each communicative activity and were instructed to produce as many of those questions as possible while maintaining a primary focus on the communication of meaning.

\section{Materials}

The testing and treatment materials consisted of communicative tasks previously used in interaction research carried out in this context (McDonough, 2005; McDonough \& Mackey, 2006). Two sets of treatment materials were compiled, and each set consisted of four communicative activities that elicited contexts for questions. The treatment materials included picture difference tasks, map tasks, personal experience and interview topics, and guessing games. Only the participants in the priming group carried out the treatment activities with the scripted interlocutors. Three sets of testing materials were also compiled, each consisting of four communicative activities that elicited 
contexts for questions. The testing tasks included picture difference tasks, story completion tasks, map tasks, and interviewing activities. The participants interacted with each other to carry out the testing materials.

\section{Procedure}

The entire study was carried out over a 7-week period, with the pretest in week 1 , treatments in week 2 , and posttests in weeks 3 and 7 . At the beginning of the study, the participants self-selected a partner with whom they would carry out the communicative activities during the pretest and both posttests. As shown in Table 1, all participants completed a biodata questionnaire and carried out the pretest in week 1. Participants assigned to the priming group were scheduled for two 20-min sessions with the scripted interlocutors in week 2, whereas the control group did not participate in any interaction. All of the participants completed two posttests: one in week 3 and the other in week 7 . The presentation of testing materials was randomized so that some participants completed one of the three sets of activities during the pretest, and others completed it during the first or second posttest. All of the interaction during the test and treatment sessions was audio-taped using a digital voice recorder placed on the table between the interlocutors.

The researcher running the experiment informed the participants that the scripted interlocutors were students at the same university who were participating in the project as part of their psycholinguistics course. In order to minimize possible discomfort triggered by the perception that the interlocutors had better English skills, the participants were not informed that the scripted interlocutors were English majors. During the treatment sessions, the researcher gave instructions for the communicative activities to both the scripted interlocutor and the participant. The scripted interlocutor was asked to speak first in order to ensure that the participants heard developmentally advanced questions before they produced any questions, thereby creating contexts for priming to occur. The interaction was not tightly controlled, however, in order to preserve as much authentic communication as possible. As a result, there was variation in the number of consecutive questions pro-

Table 1. Procedure

\begin{tabular}{lll}
\hline Week & \multicolumn{1}{c}{ Priming group } & \multicolumn{1}{c}{ Control group } \\
\hline 1 & Pretest and biodata questionnaire & Pretest and biodata questionnaire \\
2 & Two 20-min sessions with a scripted & No interaction \\
& interlocutor & Posttest 1 \\
3 & Posttest 1 & Posttest 2 \\
\hline
\end{tabular}


duced by both the participants and the scripted interlocutors. The participants interacted with a different scripted interlocutor for each of the two sessions, and the two sets of treatment materials were counterbalanced. If a participant missed a scheduled appointment or a scripted interlocutor arrived late, which happened four times, the participant carried out the tasks with a researcher. Neither the scripted interlocutors nor the researcher provided any interactional feedback in response to the participants' nontargetlike forms.

\section{Analysis}

The audio recordings of the treatment sessions were transcribed by the scripted interlocutors, and the audio recordings of the test sessions were transcribed by research assistants. The transcripts were checked by one of the researchers. For the test data, a researcher coded all questions produced by the participants according to the stages in Pienemann and Johnston's (1987) developmental sequence for ESL question formation and then assigned each participant to a stage in that sequence for each test. Stage assignment was based on the highest stage from which a participant produced two linguistically and contextually unique questions. Multiple exemplars of the same question on the same task and formulaic chunks (such as where are you from?) were not considered for stage assignment. Development was then operationalized as a stage increase on both posttests.

For the treatment data, the occurrence of syntactic priming involving developmentally advanced questions was identified. First, developmentally advanced questions were operationalized as questions from a higher stage than a participant's pretest stage. Because there was variation in the participants' initial stage assignment (either stage 3 or 4), the types of questions classified as developmentally advanced also varied. For example, if a participant had been classified as stage 3 on the pretest, then stages 4 and 5 were considered developmentally more advanced. However, if a participant had been classified as stage 4 on the pretest, then only stage 5 questions were classified as developmentally advanced (stage 6 questions were very rare in this dataset). The specific types of stage 4 and 5 questions considered in the analysis were (a) yes-no questions with an auxiliary (excluding "do you $+\mathrm{V}$ " questions, which are often formulaic chunks), (b) yes-no questions with the copula, (c) wh-questions with the copula, and (d) wh-questions with auxiliaries. Morphological errors, such as subject-verb agreement or verb tense, were not considered in the analysis.

Syntactic priming was operationalized as the tendency for speakers to produce a syntactic structure when they have just been exposed to that structure, as opposed to when they have been exposed to alternative structures. Therefore, syntactic priming was demonstrated when participants produced developmentally advanced questions after the scripted interlocutor's developmentally advanced questions more often than they produced them after the interlocutor's same level or lower level questions. For example, in (4), 
the scripted interlocutor produced a developmentally advanced question, a stage 5 question, in turn 90 . In the following turn, the participant answered the question and then produced a stage 5 question that was not a repetition of the scripted interlocutor's question but was a new question that shared the same syntactic structure (wh-fronting with auxiliary). Later in the conversation, the scripted interlocutor used a lower level question in turn 110 (a stage 4 wh-copula). However, in that context, the participant did not produce a stage 5 question. Syntactic priming was evidenced when the participant's production of developmentally advanced questions was greater after the scripted interlocutors' advanced questions than after other question types.

(4) Syntactic priming

[90] Scripted interlocutor: Why did you decide to work in Bangkok?

[91] Participant: uh because I would like to study master degree in Bangkok// what do you like to do in your free time?

[92] Scripted interlocutor: I like watching movies, especially soundtracks.

[110] Scripted interlocutor: How many clouds are in your picture?

[111] Participant: three // is there a bird?

[112] Scripted interlocutor: yeah near the woman on the right

Although the participant's question generally occurred in the turn immediately following the scripted interlocutor's question, in some cases several turns of dialogue intervened. These were embedded adjacency pairs-using Sachs, Shegloff, and Jefferson's (1974) term-that occurred between the scripted interlocutor's question and the participant's question. This is illustrated in (5). After the scripted interlocutor's question in turn 20, a wh-question with an auxiliary, the participant answered the question in turn 21, after which the researcher commented about her answer in turn 22. The participant and scripted interlocutor acknowledged the researcher's comment in turns 23 and 24 . When it was finally the participant's turn to ask a question in turn 25 , she produced a wh-question with an auxiliary.

(5) Syntactic priming with intervening dialogue

[20] Scripted interlocutor: what subject did you take?

[21] Participant: I study biotechnology

[22] Researcher: sounds very difficult

[23] Participant: yeah

[24] Scripted interlocutor: you must be smart

[25] Participant: uh where did you stay at uh six o'clock p.m.?

The intervening dialogue typically occurred when an interlocutor commented on the content of an utterance by clarifying or expressing surprise. The analysis considered only the first question produced by the participant after the end of the intervening dialogue and within 10 turns of the scripted interlocutor's question.

An independent rater coded a subset of the test and interaction data to classify questions according to stages in the developmental sequence. Simple 
percentage agreement between the researcher's and the rater's coding was $95 \%$. Alpha was set at .05 for all statistical tests.

\section{RESULTS}

The participants' production of developmentally advanced and same or lower level questions following the scripted interlocutors' questions is shown in Table 2. Overall, the participants produced more same or lower level questions (377) than developmentally advanced questions (243). Their production of same or lower level questions was not greater following the scripted interlocutor's same or lower level questions. However, the expected relationship did occur for developmentally advanced questions, with the participants producing more developmentally advanced questions after the scripted interlocutors' developmentally advanced questions (183) than after their same or lower level questions (60).

Due to the fact that there was considerable variation in the extent to which syntactic priming had occurred, the participants were further classified based on the proportion of developmentally advanced questions they produced after the scripted interlocutor's developmentally advanced questions. Because the mean proportion was .72, participants who scored higher than .72 were assigned to the high-priming group, whereas those participants who scored lower than .72 were assigned to the low-priming group. The high-priming group consisted of 19 participants whose scores ranged from .75 to $1.00(X=.86$, $S D=.09$ ), and the low-priming group consisted of 12 participants whose scores ranged from .20 to $.70(X=.49, S D=.16)$.

To determine the relationship between syntactic priming and ESL question development, the developmental outcomes for the high-priming group, the lowpriming group, and the control group were compared. As illustrated in Table 3 , only one of the participants in the control group, which had carried out only the testing tasks, advanced to a higher stage of question development. For the low-priming group, 5 out of 12 participants advanced to a higher stage of question development. Finally, for the high-priming group, 13 out of 19 partici-

Table 2. Syntactic priming during treatment tasks

\begin{tabular}{|c|c|c|c|c|c|c|}
\hline \multirow{3}{*}{$\begin{array}{l}\text { Scripted interlocutors' } \\
\text { questions }\end{array}$} & \multicolumn{6}{|c|}{ Participants' questions } \\
\hline & \multicolumn{3}{|c|}{ Advanced } & \multicolumn{3}{|c|}{ Same/lower level } \\
\hline & Sum & Mean & $\%$ & Sum & Mean & $\%$ \\
\hline Advanced & 183 & 5.90 & $75 \%$ & 202 & 6.52 & $54 \%$ \\
\hline Same/lower level & 60 & 1.94 & $25 \%$ & 175 & 5.65 & $46 \%$ \\
\hline
\end{tabular}


Table 3. Question development by group

\begin{tabular}{|c|c|c|c|c|}
\hline \multirow[b]{2}{*}{ Group } & \multicolumn{2}{|c|}{ Pretest level } & \multicolumn{2}{|c|}{ Posttest } \\
\hline & 3 & 4 & $\begin{array}{c}\text { Stage } \\
\text { increase }\end{array}$ & $\begin{array}{c}\text { No } \\
\text { increase }\end{array}$ \\
\hline High priming $(n=19)$ & 10 & 9 & 13 & 6 \\
\hline Low priming $(n=12)$ & 7 & 5 & 5 & 7 \\
\hline Control $(n=15)$ & 8 & 7 & 1 & 14 \\
\hline
\end{tabular}

pants advanced to a higher stage. The results of a chi-square test indicated that the relationship between group membership and ESL question development was significant. The analysis of the adjusted standardized residuals (Haberman, 1973) located the significance with the performance of the high-priming group $( \pm 3.1)$ and the control group $( \pm 3.3)$.

To summarize the findings, the current study found a positive relationship between syntactic priming and ESL question development. Participants who frequently produced developmentally advanced questions after hearing scripted interlocutors produce such questions moved to a higher stage of ESL question development. Thus, the findings indicate a clear positive relationship between syntactic priming and ESL question development.

\section{DISCUSSION}

Although syntactic priming was associated with ESL question development, 6 of the 19 participants in the high-priming group did not advance to a higher stage. Thus, an important question is why syntactic priming was associated with different developmental outcomes. One possible explanation relates to the role of type frequency-that is, how many different lexical items can be applied to a syntactic structure-in helping learners recognize that the structure represents a general category rather than a lexically specific construction (Ellis, 2005). Previous syntactic priming studies have shown that priming might be greater when the prime and the participant's response have the same verb (Branigan, Pickering, \& Cleland, 2000; Pickering \& Branigan, 1998), and L1 acquisition researchers have shown that young children produce developmentally advanced structures only when they can reuse high-frequency lexical items such as pronouns (Savage, Lieven, Theakston, \& Tomasello, 2003). An important question here then is whether the participants in the highpriming group differed in terms of the extent to which their developmentally advanced questions shared lexical items with the scripted interlocutors' primes. 
To explore this possibility in more detail, a post hoc analysis was carried out to determine whether the question words, subjects, main verbs, and auxiliary verbs in the scripted interlocutors' and participants' developmentally advanced questions differed. For example, the participant in (6) produced a question in turn 36 that had the same question word (what), the same subject (you), and the same verb (do) as the question produced by the scripted interlocutor in turn 35 .

(6) Syntactic priming with shared lexical items

[35] Scripted interlocutor: what did you do at one p.m.?

[36] Participant: I had lunch at one // uh in in the midnight what were you doing?

In contrast, the participant in (7) produced a question in turn 101 that had a different question word, auxiliary verb, subject, and main verb than the prime produced by the scripted interlocutor in the previous turn [100].

(7) Syntactic priming with different lexical items

[100] Scripted interlocutor: what does she look like?

[101] Participant: uh // I think she's tall // she has white skin // and long black hair // when do you have first love?

The percentage of different lexical items in the four categories (question word, subject, main verb, and auxiliary verb) was calculated. As shown in Figure 1, for the participants who developed, $58 \%$ of their questions had a different question word than the one used by the scripted interlocutors, but only $39 \%$ of the participants who did not develop used different question words. A more

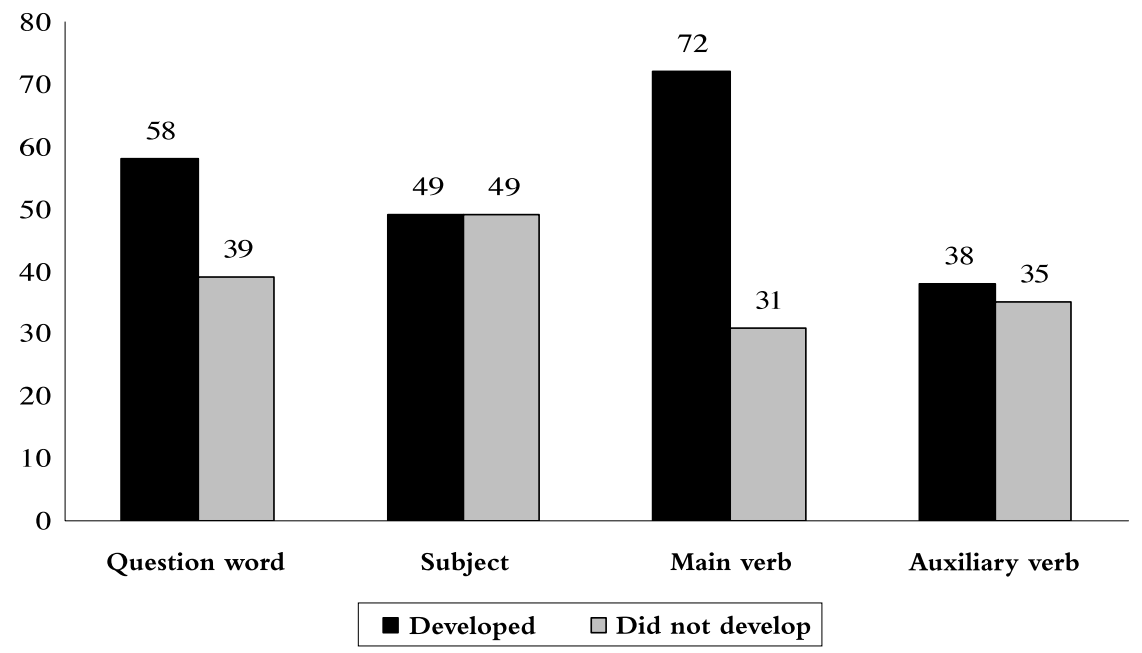

Figure 1. Percentage of participants' questions with different lexical items. 
striking pattern was found for main verbs: Whereas $72 \%$ of the targets produced by the participants who developed contained a different main verb than the scripted interlocutors' question, this occurred for only $31 \%$ of the questions produced by the participants who did not develop. For auxiliary verbs and subjects, there was little difference between those participants who did and did not develop. Thus, the post hoc analysis indicated that those highpriming participants whose questions contained different question words and main verbs developed, whereas the participants who reused the lexical items provided in the scripted interlocutors' questions did not develop. The findings suggest that syntactic priming might be associated with L2 developmental outcomes when participants apply the syntactic structure to a wide variety of question words and main verbs.

An interesting parallel between the findings of the current study and those of McDonough and Mackey (2006) concerns the issue of repetition. As several researchers have suggested, productively using a form in one's own way might be more beneficial for development than simply repeating or mimicking that form (Gass, 2003; Panova \& Lyster, 2002). McDonough and Mackey found that immediate repetition of a recast was not associated with ESL question development, but subsequently producing the question form modeled in the recast was predictive of development. Similarly, in the current study, syntactic priming that involved the same lexical items produced by the scripted interlocutors was not associated with development, but priming that involved different question words and verbs was related to development. Taken together, the findings of the two studies suggest the importance of learners' productive use of developmentally advanced questions for ESL question development, as opposed to simple repetition of question forms provided by an interlocutor.

The current study was conducted in a university-level program in a foreign language setting. It is possible that the setting might have an impact on the developmental outcomes of interaction, particularly in the light of questions about foreign language versus L2 settings (Mackey \& Goo, 2007). Thus, these results might not be easily generalizable to other learners and settings. The results reported here need to be interpreted with caution due to the fact that only one target linguistic item was investigated. Future research would profit from investigating a larger array of linguistic targets as well as target languages. Caution in interpreting the findings is also needed due to the short-term nature of the experiment. Some researchers argue that shortterm treatments providing a limited amount of exposure to targeted linguistic items might not accurately represent how overall effective a longer time interactional treatment could be; future research might thus benefit from increasing the amount of interaction time (Long, 2006; Long et al., 1998). Furthermore, a longitudinal study employing delayed posttests could shed more light on the relationship between priming and L2 development. Additionally, because the current study examined only university-level learners of English (all of whom were native speakers of Thai), future studies would also benefit from examining more diverse groups of learners, employing participants who 
vary not only in terms of proficiency, setting, and L1 but also in terms of other individual differences, such as working memory capacity, that might mediate the interaction-learning relationship noted in the literature. It is also possible that learners' particular aptitudes might predispose some of them to benefit, or not, from the implicit learning processes associated with syntactic priming. The inclusion of measures of individual differences might benefit future studies that investigate these relationships. Research in these areas might help to explain why some participants produced questions that shared lexical items with the scripted interlocutors' questions, whereas other participants produced questions with different lexical items.

This study attempted to bridge the gap between syntactic priming research in psychology and interaction research in SLA. To achieve this, we used the scripted interlocutor technique created by psychologists (Branigan et al., 2000). As originally devised, this technique involves a great deal of control over turntaking, which is generally not desirable in interaction research where communication is generally as authentic as possible. Consequently, we had to reduce the level of control generally associated with syntactic priming research in order to increase the validity of the interactional context. As a result, the interaction between the scripted interlocutors and participants involved consecutive utterances and the intervening dialogue described previously. Although these issues certainly make the analysis and drawing of conclusions more complicated, messy data is, of course, inherent in the nature of interaction.

Whereas previous interaction research has suggested that interactional feedback may be more beneficial for L2 learning than models (Iwashita, 2003; Leeman, 2003; Long et al., 1998), our findings suggest that models might also contribute to L2 learning when learners have opportunities to produce the syntactic structures contained in the models. As noted earlier, the output opportunities in this study seem to have promoted L2 development when learners generated new sentences that contained the modeled form but not when they simply repeated many of the lexical items in the model. It might be interesting to consider such findings in light of DeKeyser's (1998) cognitivepsychological view of L2 learning. The learners who produced creative sentences that included developmentally advanced question forms could be seen as learners in later stages of skill acquisition (i.e., automatizing or fine-tuning procedural knowledge), whereas those who just repeated the model might be seen as undergoing practice for proceduralization of knowledge. This is compatible with current formulations of the interaction hypothesis (Gass \& Mackey, 2007; Long, 1996), which states that various combinations of input and output features might be developmentally helpful. For instance, while engaging in conversation, learners might perceive negative evidence provided through negotiation or overt correction as an alert to problematic aspects of their interlanguage, and they might use output to test a hypothesis they might have come up with about the accuracy of target language. Obviously, additional research is necessary to determine under which conditions models facilitate primed production and to clarify whether models alone 
are associated with development. In this short-term study, primed production during interaction was associated with ESL question development, and we suggest that syntactic priming might be one of the sources of interactiondriven L2 learning.

\section{(Received 1 February 2007)}

\section{REFERENCES}

Bock, K. (1986). Syntactic persistence in language production. Cognitive Psychology, 18, 355-387.

Bock, K. (1989). Closed-class immanence in sentence production. Cognition, 31, 163-186.

Bock, K. (1990). Structure in language: Creating form in talk. American Psychologist, 45, 1221-1236.

Bock, K., \& Griffin, Z. (2000). The persistence of structural priming: Transient activation or implicit learning? Journal of Experimental Psychology: General, 129, 177-192.

Bock, K., \& Loebell, H. (1990). Framing sentences. Cognition, 35, 1-39.

Bock, K., Loebell, H., \& Morey, R. (1992). From conceptual roles to structural relations: Bridging the syntactic cleft. Psychological Review, 99, 150-171.

Branigan, H., Pickering, M., \& Cleland, A. (2000). Syntactic co-ordination in dialogue. Cognition, 75, B13-B25.

Branigan, H., Pickering, M., Liversedge, S., Stewart, A., \& Urbach, T. (1995). Syntactic priming: Investigating the mental representation of language. Journal of Psycholinguistic Research, 24, 489-506.

Branigan, H., Pickering, M., Stewart, A., \& McLean, J. (2000). Syntactic priming in spoken production: Linguistic and temporal interference. Memory \& Cognition, 28, 1297-1302.

de Bot, K. (1996). The psycholinguistics of the output hypothesis. Language Learning, 46, 529-555.

DeKeyser, R. (1998). Beyond focus on form: Cognitive perspectives on learning and practicing second language grammar. In C. J. Doughty \& J. Williams (Eds.), Focus on form in classroom second language acquisition (pp. 42-63). New York: Cambridge University Press.

Ellis, N. C. (1998). Emergentism, connectionism, and language learning. Language Learning, 48, 631-664.

Ellis, N. C. (2002a). Frequency effects in language acquisition: A review with implications for theories of implicit and explicit language acquisition. Studies in Second Language Acquisition, 24, 143-188.

Ellis, N. C. (2002b). Reflections on frequency effects in language acquisition: A response to commentaries. Studies in Second Language Acquisition, 24, 297-339.

Ellis, N. C. (2005). Constructions, chunking and connectionism: The emergence of second language structure. In C. J. Doughty \& M. H. Long (Eds.), The handbook of second language acquisition (pp. 63-103). Oxford: Blackwell.

Ellis, R. (1991). The interaction hypothesis: A critical evaluation. In E. Sadtano (Ed.), Language acquisition and the second/foreign language classroom (pp. 179-211). Singapore: Regional English Language Centre.

Gass, S. M. (1997). Input, interaction, and the second language learner. Mahwah, NJ: Erlbaum.

Gass, S. M. (2003). Input and interaction. In C. J. Doughty \& M. H. Long (Eds.), Handbook of second language acquisition (pp. 224-255). Oxford: Blackwell.

Gass, S. M., \& Mackey, A. (2007). Input, interaction and output in second language acquisition. In B. VanPatten \& J. Williams (Eds.), Theories in second language acquisition (pp. 175-199). Mahwah, NJ: Erlbaum.

Haberman, S. (1973). The analysis of residuals in cross-classified tables. Biometrics, 29, 205-220.

Hare, M., \& Goldberg, A. (1999). Structural priming: Purely syntactic? In M. Hahn \& S. Stones (Eds.), Proceedings of the 21st annual meeting of the Cognitive Science Society (pp. 208-211). Mahwah, NJ: Erlbaum.

Havranek, G. (2002). When is corrective feedback most likely to succeed? International Journal of Educational Research, 37, 255-270.

Huttenlocher, J., Vasilyeva, M., \& Shimpi, P. (2004). Syntactic priming in young children. Journal of Memory and Language, 50, 182-195.

Iwashita, N. (2003). Negative feedback and positive evidence in task-based interaction. Studies in Second Language Acquisition, 25, 1-36.

Keck, C., Iberri-Shea, G., Tracy-Ventura, N., \& Wa-Mbaleka, S. (2006). Investigating the empirical link between task-based interaction and acquisition: A meta-analysis. In J. Norris \& L. Ortega 
(Eds.), Synthesizing research on language learning and teaching (pp. 91-131). Amsterdam: Benjamins.

Leeman, J. (2003). Recasts and second language development: Beyond negative evidence. Studies in Second Language Acquisition, 25, 37-63.

Loewen, S., \& Philp, J. (2006). Recasts in the adult English L2 classroom: Characteristics, explicitness, and effectiveness. Modern Language Journal, 90, 536-556.

Long, M. H. (1996). The role of the linguistic environment in second language acquisition. In W. Ritchie \& T. K. Bhatia (Eds.), Handbook of language acquisition: Vol. 2. Second language acquisition (pp. 413-468). San Diego, CA: Academic Press.

Long, M. H. (2006). Problems in SLA. Mahwah, NJ: Erlbaum.

Long, M. H., Inagaki, S., \& Ortega, L. (1998). The role of interactional feedback in SLA: Models and recasts in Japanese and Spanish. Modern Language Journal, 82, 357-371.

Mackey, A. (1999). Input, interaction, and second language development: An empirical study of question formation in ESL. Studies in Second Language Acquisition, 21, 557-587.

Mackey, A., \& Goo, J. (2007). Interaction research: A meta-analysis and research synthesis. In A. Mackey (Ed.), Conversational interaction in second language acquisition: A collection of empirical studies (pp. 407-452). Oxford: Oxford University Press.

McDonough, K. (2005). Identifying the impact of negative feedback and learners' responses on ESL question development. Studies in Second Language Acquisition, 27, 79-103.

McDonough, K. (2006). Interaction and syntactic priming: English L2 speakers' production of dative constructions. Studies in Second Language Acquisition, 28, 179-207.

McDonough, K., \& Mackey, A. (2006). Responses to recasts: Repetitions, primed production and linguistic development. Language Learning, 54, 693-720.

Melinger, A., \& Dobel, C. (2005). Lexically-driven syntactic priming. Cognition, 98, B11-B20.

Nobuyoshi, J., \& Ellis, R. (1993). Focused communication tasks and second language acquisition. ELT Journal, 47, 203-210.

Panova, I., \& Lyster, R. (2002). Patterns of corrective feedback and uptake in an adult ESL classroom. TESOL Quarterly, 36, 573-595.

Pica, T. (1994). Research on negotiation: What does it reveal about second-language learning conditions, processes, and outcomes? Language Learning, 44, 493-527.

Pickering, M., \& Branigan, H. (1998). The representation of verbs: Evidence from syntactic priming in language production. Journal of Memory and Language, 39, 633-651.

Pienemann, M. (1998). Language processing and second language development: Processability theory. Amsterdam: Benjamins.

Pienemann, M. (2007). Processability theory. In B. VanPatten \& J. Williams (Eds.), Theories in second language acquisition (pp. 137-154). Mahwah, NJ: Erlbaum.

Pienemann, M., \& Johnston, M. (1987). Factors influencing the development of language proficiency. In D. Nunan (Ed.), Applying second language acquisition research (pp. 45-141). Adelaide, Australia: National Curriculum Resource Centre, AMEP.

Pienemann, M., Johnston, M., \& Brindley, G. (1988). Constructing an acquisition-based procedure for second language assessment. Studies in Second Language Acquisition, 10, 217-243.

Sachs, H., Shegloff, E. A., \& Jefferson, G. (1974). A simplest systematic for the organization of turntaking for conversation. Language, 50, 696-735.

Savage, C., Lieven, E., Theakston, A., \& Tomasello, M. (2003). Testing the abstractness of children's linguistic representations: Lexical and structural priming of syntactic constructions in young children. Developmental Sciences, 6, 557-567.

Schmidt, R. (1995). Consciousness and foreign language learning: A tutorial on the role of attention and awareness in learning. In R. Schmidt (Ed.), Attention and awareness in foreign language learning (Tech. Rep. No. 9, pp. 1-63). Honolulu: University of Hawai'i Press.

Schmidt, R. (2001). Attention. In P. Robinson (Ed.), Cognition and second language instruction (pp. 332). New York: Cambridge University Press.

Silver, R. E. (2000). Input, output, and negotiation: Conditions for second language development. In B. Swierzbin, F. Morris, M. E. Anderson, C. A. Klee, \& E. Tarone (Eds.), Social and cognitive factors in second language acquisition: Selected proceedings of the 1999 Second Language Research Forum (pp. 345-371). Somerville, MA: Cascadilla Press.

Spada, N., \& Lightbown, P. (1999). Instruction, first language influence, and developmental readiness in second language acquisition. Modern Language Journal, 83, 1-22. 
Swain, M. (1995). Three functions of output in second language learning. In G. Cook \& B. Seidlhofer (Eds.), Principle and practice in applied linguistics: Studies in honour of H. G. Widdowson (pp. 125144). Oxford: Oxford University Press.

Swain, M. (2000). The output hypothesis and beyond: Mediating acquisition through collaborative dialogue. In J. P. Lantolf (Ed.), Sociocultural theory and second language learning (pp. 97-114). Oxford: Oxford University Press.

Swain, M. (2005). The output hypothesis: Theory and research. In E. Hinkel (Ed.), Handbook of research in second language teaching and learning (pp. 471-484). Mahwah, NJ: Erlbaum.

Swain, M., \& Lapkin, S. (1995). Problems in output and the cognitive processes they generate: A step towards second language learning. Applied Linguistics, 16, 371-391.

Tomasello, M. (2000). The item-based nature of children's early syntactic development. Trends in Cognitive Science, 4, 156-163. 